\title{
InfoNorth
}

\section{Science in the Yukon: Advancing a Vision for Evidence-based Decision Making}

\author{
by Aynslie E. Ogden, Michael Schmidt, Bob Van Dijken and Lacia Kinnear
}

$\mathrm{I}$

N ORDER FOR SCIENTIFIC KNOWLEDGE to inform decision making (science for policy), policy that sup1 ports and cultivates scientific activity (policy for science) is required. Recent public policy announcements - including the appointment of Canada's first Federal Minister of Science (November 2015), the release of the Government of Yukon Science Strategy (January 2016), the release of the Pan-Northern Approach to Science (April 2016), and the pending appointment of a National Chief Science Officer-indicate that both federal and territorial governments recognize the value of timely and robust knowledge in informing decision making.

The issues facing the North, such as climate change, resource development, and social transformations, are complex and interconnected (CCA, 2008). Territories are emphasizing the importance of advancing scientific research that benefits and meets the solution-oriented information needs of Northerners (GY, GNWT and GN, 2016). Solution-oriented science considers from the start, while framing the research questions, how results can be implemented in policy, practice, and programs, and it selects research projects that will address pressing issues. It can include basic science (e.g., baseline monitoring across the North), better application of existing knowledge (improving knowledge transfer and mobilization), applied research, or a combination (Pope, 2015).

Northern Canada is at the forefront of efforts to advance a participatory paradigm for the conduct of research, one that involves meaningful involvement and engagement of local peoples. Resetting the relationship with Indigenous peoples, as called for by the Truth and Reconciliation Commission, can be advanced by the science we choose to do and how we do it. It is essential to ensure that scientific and traditional knowledge are equally reflected in northern research and to respect the right of Indigenous governments and peoples to set guidelines for ownership of, access to, and use of their traditional knowledge (GY, GNWT and GN, 2016).

The vision of the 2016 Government of Yukon Science Strategy is to support the active pursuit, gathering, and storage of scientific knowledge so it can be easily retrieved, transferred, shared, and used to support evidence-based decision making (GY, 2016a). This article discusses the context of this solution-driven vision and how it can be advanced in Yukon.

\section{SCIENCE TO BENEFIT YUKON RESIDENTS}

Understanding how the activities, interests, and needs of the Government of Yukon, Yukon First Nations, Yukon College, the federal government, and universities have evolved over the years offers insight into the work still needed to advance science that benefits Yukoners.

\section{Government of Yukon}

The first Government of Yukon science policy, released in 1986, arose from the government's recognition that science, research, and technology are "prime movers of economic revival and socio-economic growth" (GY, 1986). This policy was considered a first step toward developing local scientific and technological capabilities. It was intended to be a clear signal to federal science organizations, granting agencies, and universities that the Government of Yukon was preparing to take a more active role in determining the nature and scope of science within its jurisdiction.

While Yukon researchers and agencies have historically relied on federal funding for northern science activities, science funding was not specifically negotiated in the final Yukon devolution transfer agreement. This fact did not prevent the Government of Yukon from developing scientific partnerships and advancing scientific endeavours, but it may have limited them. The Government of Yukon has developed in-house scientific capacity, particularly in the fields of geoscience, archaeology, paleontology, and environmental and natural resource management. Many Government of Yukon science practitioners have made significant contributions to their field, to decision making within the territory, and to meaningful local partnerships, as well as to national and international scientific efforts. The Government of Yukon has also enabled scientific activity outside its organization by supporting scientific institutional development at Yukon College, maintaining a network of research facilities (GY, 2016b), and publishing online databases and datasets (GY, 2016c).

Today, government support for science is more critical than ever, given the rapidity and extent of change facing the North in the 21st century. Science underpins the sustainable management of lands, waters, and natural resources and the delivery of evidence-based health and social services, and 
it assists in responding to emerging issues. However, it is neither pragmatic nor efficient for governments to rely on outside agencies to provide all of the scientific information required to support decision making; they must be able to address some of their scientific information gathering and research needs in-house. A symbiotic relationship between government and non-government science is essential. Government(s) in Yukon have an important role to play in fostering, promoting, and supporting scientific activity and developing and sustaining scientific capacity.

It is within this context that the Government of Yukon released its 2016 Science Strategy. A long-term approach to developing science capacity in Yukon, this new strategy demonstrates that the Government of Yukon values the role of science in informing decision making and the contribution of science and innovation to the economy. The strategy recognizes the important contributions of traditional and local knowledge and encourages their incorporation in research projects and decision making. In the near term, the strategy seeks to enhance the Government of Yukon's ability to access, apply, and develop scientific knowledge and to support new research and development activities by advancing work on six goals (Table 1). The Government of Yukon has committed to accelerating and stimulating science and research capacity and application and announced its intention to develop a companion document to the science strategy that will outline initiatives to foster and increase research and development (R\&D) investment in Yukon.

\section{Yukon First Nations}

The need for targeted research, the importance of local leadership and involvement in research, and the importance of disseminating research results locally was articulated in Together Today for Our Children Tomorrow, the first statement of grievances and principles for negotiating a land claim made by Yukon's First Nations (Council for Yukon Indians, 1973). These conditions included having a say in what research is conducted and by whom; ensuring involvement in, ownership of, and access to the research; and developing the necessary skills to conduct research themselves. Together Today also noted specific research needs, which included finding solutions for problems and considering all aspects of northern development as it affects Yukon First Nations.

The Umbrella Final Agreement and subsequent 11 individual Yukon First Nation land claim and self-government agreements contain provisions to govern and manage the territory using both traditional knowledge and modern science (Table 2). Yukon First Nations have taken on leadership roles in research both within their traditional territories and in national and international projects. Research led by and carried out in collaboration with Yukon First Nations, on topics ranging from contaminants to climate change to caribou, has contributed significantly to our knowledge of Yukon and shown how scientific, traditional, and local knowledge together can broaden and enrich our understanding more than one way of knowing on its own (e.g., Schuster et al., 2011; Wesche et al., 2011; Wolfe et al., 2011; Russel et al., 2013).

Yukon First Nations have adopted policies that govern the conduct of scientific research within their traditional territories. In 2007, the Council of Yukon First Nations passed a resolution to adopt the First Nations Principles of Ownership, Control, Access, and Possession of Traditional Knowledge (LDR Resolution NO782/06; NAHO, 2005). A number of Yukon First Nations, including the Vuntut Gwich'in and Trondek Hwech'in First Nations, have established licensing processes for research on their settlement lands. Such policies emphasize:

- The authority of First Nations to control data collection in their communities;

- The strong desire for research partnerships that meet local information needs;

- Meaningful involvement of local people and agencies in research design, delivery, analysis, and communication of results;

- The need for local benefits from research, ranging from learning about the results of studies conducted within their traditional territories to employment and training opportunities.

Co-management and co-governance, as envisioned in Yukon land claims, require engagement and understanding. In pursuing a Yukon science vision, building on the unique elements of these agreements that empower local people is critical to successful partnerships in knowledge co-production.

\section{Yukon College}

The Yukon Vocational and Technical Training Centre (1963) evolved into Yukon College (1983). The college has grown and adapted its academic programs to serve the changing territory, seeking to balance the often competing needs to provide a vision for post-secondary education, address the immediate training needs of industry and government, and respond to the needs of its students (Barnes and Graham, 2015). Part of the college's strategy for supporting territorial development was building its own research capacity, "encouraging the indigenization of northern scholarship and facilitating northern research that is done in the North, by the North, and for the North" (Easton, 2008:154).

In 2009, the Government of Yukon provided funding to consolidate and further develop research programming at Yukon College under the umbrella of the Yukon Research Centre, whose scientists and engineers have made significant contributions to advancing knowledge and understanding of the territory (e.g., Stewart and Janin, 2014; Benkert et al., 2015; Calmels et al., 2015; Perrin et al., 2015).

Yukon College is now poised to take the next steps in its evolution and is well on its way to becoming 
TABLE 1. Goals and strategic initiatives of the 2016 Government of Yukon Science Strategy (GY, 2016a).

Goal (Long-term) Strategic initiative (near-term)

\section{Support decision making:}

To develop scientific knowledge and sciencebased solutions to support and enhance decision making and innovation.
1. Identify and communicate science needs

2. Conduct necessary research

3. Support evidence-based decision making

4. Link science to policy development and decision making

5. Produce accessible and understandable science

6. Support innovation that is linked to organizational goals and objectives

7. Develop a companion research strategy

1. Cultivate scientific partnerships

2. Support training and professional development

3. Enhance recruitment and retention of science practitioners and professionals

4. Support science education

5. Support the Yukon Research Centre

6. Support industry's science capacity

1. Enhance baseline and long-term data collection

2. Standardize data collection protocols

3. Enhance data openness

4. Preserve datasets for long-term use

5. Undertake data management planning

6. Increase data collaboration at local, regional, national and international scales

1. Promote and encourage innovation and commercialization

2. Support and encourage R\&D investment by the private sector

3. Support knowledge sector business development

4. Support industry partnerships

5. Support the development of science and technology as a secondary industry

6. Encourage innovation through flexible policies

1. Support and enhance internal information sharing

2. Support and enhance outreach

3. Inventory Government of Yukon science assets, interests and needs

4. Enhance access to sound and reliable scientific information

5. Increase publication of Government of Yukon science

6. Enhance library services

7. Share information promptly

1. Enhance consistency in government-wide operational science policies and procedures

2. Enhance data capture and standardization of data collected by outside agencies

3. Ensure effective and appropriate oversight of scientific activity in Yukon

4. Facilitate and promote scientific excellence coordination, ensure the effective oversight of scientific activity, and facilitate and promote scientific excellence.

a university-Yukon University. The university will be a hybrid model that offers a full range of programming, including trades, academic readiness, certificates, diplomas and degrees, and will expand research opportunities for students and faculty. The 12 community campuses, operating as a crossterritorial network, will continue to play a critical role in delivering education and training throughout the Yukon (YC, 2016).

\section{Federal Government}

In 2000, after a decade of declining federal investment in northern research, the Natural Sciences and Engineering Research Council of Canada (NSERC) and Social Science and Humanities Research Council (SSHRC) convened a task force on northern research. Their watershed report, From Crisis to Opportunity: Rebuilding Canada's Role in Northern Research (Task Force on Northern Research, 
TABLE 2. Provisions within the Umbrella Final Agreement (GC, CYI and GY, 1993) to govern and manage the territory that rely on both traditional knowledge and modern science and around the conduct of heritage-related research.

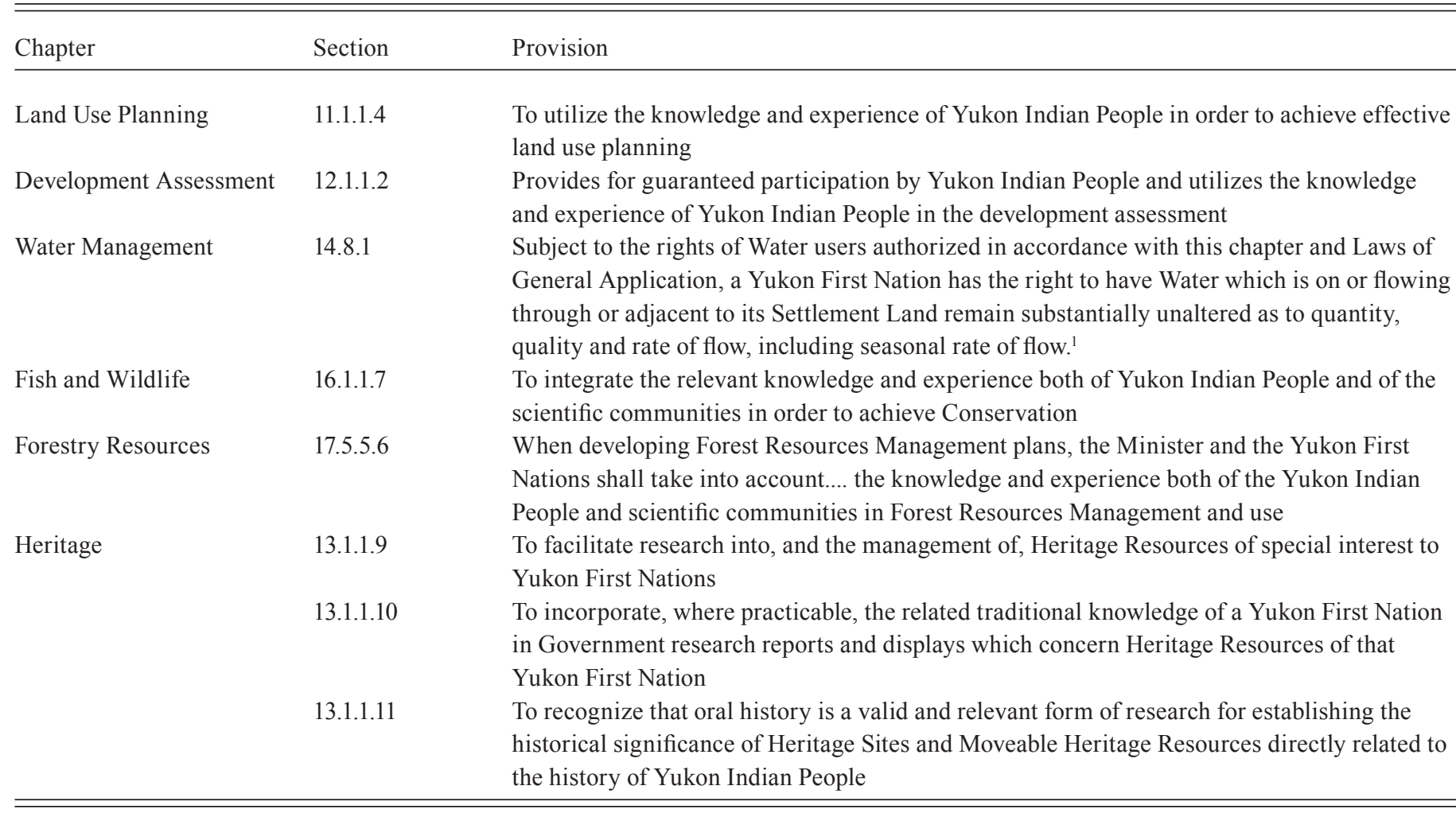

${ }^{1}$ To enable this provision an understanding of baseline conditions is necessary as well as a strong monitoring regime.

2000), described a "state of crisis" in northern science and influenced a decade or more of northern science policy. The task force recognized that a decline in science capacity at this scale could not be reversed by a quick solution, but would require a long-term program of capacity building and renewal. The report recommendations stressed the need for a new joint NSERC/SSHRC initiative to enhance northern research, as well as a federal strategy for northern science and technology, noting that the lack of such a strategy makes northern research more vulnerable in times of financial stress.

The success of the task force in developing northern research capacity has yet to be assessed comprehensively. However, it is clear that subsequent federal investments in Arctic science-including the NSERC Northern Chairs program, ArcticNet, International Polar Year, Arctic Research Infrastructure Fund, Canadian High Arctic Research Station, Churchill Marine Observatory, National Research Council Arctic Program, and most recently, Sentinel North-have been substantial and have helped Arctic science start to emerge from a state of crisis. How well coordinated these efforts have been remains an open question.

Most federal science initiatives have identified engagement and partnerships with northern organizations as a major goal. However, many northern agencies and researchers believe that such initiatives have not met northern needs for information and capacity building. Critics have cited the limited geographic focus (on the eastern and High Arctic), the emphasis on capacity building in southern universities, and the degree to which local partnerships and capacity were cultivated. The fact that investment decisions are made largely outside the North is also significant because these decisions have a tremendous influence on what scientific information is available to northern decision makers (Ogden and Thomas, 2013; Moffit et al., 2015). Often, the scientific interests and needs of southern institutions are not aligned with those of northern institutions, leaving the latter unaddressed. It could be argued that success in addressing northern needs depends on effective and meaningful governance models and collaborative processes and the ability of Northerners to engage in partnership development through these processes.

Carr et al. (2013) provided the first empirical estimate of the local economic impact of publicly funded research expenditures in the territories between 2000 and 2009. The total spending on northern research during this period was estimated to be $\$ 284$ million, and annual spending peaked in 2009 at nearly $\$ 110$ million. Clearly, Northerners are benefiting from a level of science investment that is beyond the capacity of northern agencies (Ogden and Thomas, 2013). However, even at its peak, northern research affected the territorial GDP by only $0.04 \%$, income by $0.09 \%$, and employment by $0.11 \%$. These figures indicate that much can be done to increase income, employment, and other benefits from the research enterprise in the North. 
Canada is continuing to invest in Arctic science. Polar Knowledge Canada (POLAR) was created by the Canadian High Arctic Research Act, which came into force on 1 June 2015. Its purpose is to strengthen Canada's international position as a leader in polar science and technology. POLAR is not resourced to reverse the impact on northern research of Canada's declining R\&D effort (as measured by the ratio of government R\&D/GDP, which declined from $2.1 \%$ in 2001 to $1.63 \%$ in 2013). Nor can it reverse the decline in federal in-house R\&D (Dufor, 2015) or accommodate the financial needs created by the pending sunset of ArcticNet.

To build on the momentum developed over the past 15 years, northern research needs to renew and sustain funding that increases the capacity of northern organizations to engage in and help to determine the next stage in the evolution of northern research. An independent assessment of what has been accomplished since the release of the 2000 task force report would be extremely helpful.

\section{Universities}

Universities are critical to advancing knowledge and understanding of Canada's North. As articulated in a set of commitments to Canadians, universities have committed to putting their best minds to the most pressing problems to help build a stronger Canada through collaboration and partnerships (Universities Canada, 2015).

In Canada's North, the need to include stakeholders and communities in the scientific process is now almost universally recognized because of the many issues that communities need to address (Southcott, 2011). While universities have received numerous requests to develop new, creative ways of making northern research be more responsive to regional needs, evidence shows that academics have been slow to adapt to this new paradigm. Brunet et al. (2014a), who conducted the first empirical evaluation of the extent to which there has been a paradigm shift towards more participatory approaches in northern research, found only a slight increase in these approaches over the last half century.

Universities involved in northern research have long reported that securing the funds to establish and sustain strong partnerships and good two-way communications is challenging. Funding has presented a serious barrier to creating the necessary partnerships among the different stakeholders involved. The high costs of northern research and declining funding and resources available to support such work contributed to the erosion of northern research capacity at Canadian universities in the 1990s. In addition, review boards for research funding agencies had limited northern representation and failed to take into account the significant costs (e.g., for travel, lodging, and translation) and time lines needed to consult with Northerners and report research results.

Researchers involved with the Social Economy Network of Northern Canada have shared insights into the challenges and opportunities of developing northern partnerships that go beyond funding. These include operating in a large geographic study area with diverse population, cultural groups, and languages, and the legacy of past colonial experiences (Southcott et al., 2011; Brunet et al., 2016). Evidence of the lack of social capital (trust and reciprocity) between researchers and communities, along with the perception that researchers benefit more from research partnerships than their community partners, was also detrimental to science partnerships. Successful community-researcher partnerships have been attributed to local engagement at the proposal, research design, and result dissemination phases; the hiring of community researchers; funding and performance assessment processes; leadership and capacity at the community level; and the timing and perceived transparency of communicating results (Brunet et al., 2014b, 2016).

\section{LESSONS LEARNED}

The Government of Yukon Science Strategy (GY, 2016a) identifies 10 principles to guide how science is performed and used, with the overall aim of advancing evidence-based decision making. Each of these principles is discussed below within a broader northern context.

\section{Recognize the Importance of Science and Innovation}

Science is a fundamental part of Canadian culture and society, leading to new goods and services, improvements in health and well-being, and a better understanding of the causes and effects of changes in our environment (CCA, 2014). Science and technology provide the knowledge and the means to manage the challenges facing Yukon in the areas of housing, infrastructure, energy, healthcare, resource management, climate change, and more. Innovation can result in opportunities and solutions; it is essential to continued economic growth, prosperity and competitiveness (CCA, 2013). Science can help to minimize the unintended consequences of policy decisions by enabling a more informed analysis of the trade-offs of alternative policy choices. Governments around the world, the Government of Yukon among them, recognize that scientific knowledge is a key component in addressing societal issues and problems and that government has a responsibility to foster an environment that supports its science community. Accepting the importance of science in informing decisions is the first step to advancing evidence-based decision making.

\section{Incorporate Traditional and Local Knowledge}

Traditional and local knowledge are valid and essential sources of information and knowledge systems that are complementary to scientific knowledge. These distinct intellectual traditions, developed in different institutional and cultural settings, generate different theories about the natural world (Cruikshank, 1981). Respect for Indigenous ways of knowing and their incorporation in research 
projects and decision making in the North have been widely encouraged and practiced. Local Indigenous knowledge has emerged in recent years at the global science-policy interface as an influential contributor (UNESCO, 2015). Indigenous, local, and traditional knowledge systems are acknowledged as major resources for increasing the effectiveness of efforts to adapt to climate change, but use of these knowledge systems is inconsistent (IPCC, 2014). The unique nature of land-claim agreements in Yukon provides a real opportunity to advance work at the interfaces of science with policy, science with Indigenous knowledge, and Indigenous knowledge with policy to truly reflect the northern knowledge-policy interface as a three-way, rather than a two-way, relationship.

\section{Focus on Needs}

The Government of Yukon has stated that its scientific activities will be linked to established needs in order to better address the many issues and challenges facing northern residents. Nunavut and Yukon Science Advisors have commented on the importance of a northern voice in determining what knowledge is needed, and correspondingly what research is funded (Ogden and Thomas, 2013). However, stated science priorities, recognized societal needs, and funding patterns of the major North American and European agencies are poorly aligned (Ibarguchi et al., 2015; Rosen, 2016). Greater alignment can be achieved by involving northern agencies in research priority-setting, proposal review, and funding allocation processes, as well as by allowing non-academic principal investigators to receive funding (Brunet et al., 2016). Leveraging interests and investments at local and regional scales through partnerships can help to direct attention to areas of greatest need.

\section{Improve Coordination}

Coordinating scientific efforts will support integrated science among departments and agencies. Significant efforts have been made over the past several decades to enhance scientific coordination and it is critical that this work continue (e.g., Sloan and Hik, 2007; Callaghan et al., 2015). Effective coordination prevents duplication, increases efficiency, and facilitates exchanges and transfers of data and information between government, industry, and academic organizations and scientists. Innovations are increasingly the product of interdisciplinary endeavors, making the role of coordination that much more important.

\section{Provide Appropriate Resources for Scientific Activities}

Science involves long-term activities that require significant human and financial resources. While the even more limited resources available to support scientific work within smaller (e.g., territorial and First Nation) governments necessitate a focus on resourcing those activities that are most urgently needed, stable financial support for scientific activities is essential. Such support involves a commitment to sustain core capabilities, which include the institutional bodies responsible for supporting northern science, the necessary physical infrastructure, and the human capacity required to provide, retain, and use knowledge (Hik, 2009). Interestingly, despite the global financial crisis, global expenditures on research and development have grown faster than the global economy, reflecting confidence that investing in science will bring future benefits (UNESCO, 2015).

Communication is a key element of the basic infrastructure requirements to support scientific activities and is a challenge in many remote areas in the North. Analysis of data in real time (real-time analytics) is far more effective than trying to paste data sets together after the fact. Examples are the use of real-time meteorological data from ground and spaceborne sensors in weather forecasting and the use of webcams for up-to-date reporting of road conditions and landslide monitoring. Widespread access to cellular networks for data collection and communication, as well as access to reliable high-speed Internet, will greatly facilitate real-time analytics. Reliable high-speed Internet is also an enabler for all communities to use the very large, open-domain data sets now available, including satellite imagery and remote sensing data, as well as real-time terrestrial networks, and to foster networking and sharing of data and ideas.

\section{Keep Pace with Development}

Government science programs and activities help identify industrial and resource developments that are ecologically sustainable, socially acceptable, and economically sound. The Government of Yukon has recognized that the breadth and depth of government science programs must keep pace with industrial innovation and activity to ensure that scientific analyses are available to consider when government makes decisions. The Government of Yukon has also recognized its role in promoting the adoption of technological advances that facilitate sustainable development (e.g., by promoting energy efficiency) and adaptation to climate change.

\section{Keep Current with Scientific Advances}

Scientific advances are made at a rapid rate. Keeping up to date with relevant scientific information is critical to being able to use the best available knowledge to guide decisions and activities. Keeping up can be a particular challenge for governments and agencies in the North, where access to scientific journals and capacity to review and assess recent literature can be limited, and scientific information may not be available in formats that are easy to access and digest. In this regard, developing collaborative research partnerships (Tondu et al., 2014); enhancing data openness (GC, 2007; IASC, 2013); maintaining 
and improving scientific information management systems for easy retrieval, sharing and use of data; and promoting knowledge exchange and translation would all help Northerners to keep current.

\section{Promote Health and Social Sciences}

Historically, research in health sciences, social sciences and humanities in the Canadian North has received less funding than research in other fields (Chatwood and Young, 2010; Young and Chatwood, 2011; Giles, 2014). The funding discrepancy is reflected in the smaller number of publications in health and social sciences compared to earth, space, and biological sciences and in the relatively low scientific impact of the former (Côté and Picard-Aitken, 2009). However, these underfunded fields play an essential role in enhancing the quality of life of Yukoners. For example, social sciences help decision makers gain a better appreciation of the unique needs, attitudes, and perceptions of diverse Yukon communities and inform understanding of and responses to complex emerging issues. Enhancing research in social sciences and humanities also shifts the focus to people and places, drawing attention to the diversity of northern cultures, political systems, demographics, histories, languages, and legal systems and thus counteracting the concept of the Arctic as a place of polar bears and icebergs (IASSA, 2016). Health systems and implementation research can help identify the approaches best suited to improving health and well-being in rural and remote communities throughout the North and the circumpolar world.

Very little of the health research conducted in the North in recent decades has been initiated by Northerners themselves (J. Butler Walker, Arctic Institute of Communitybased Research, pers. comm. 2016). Yet, despite low resource allocations, community-based organizations took steps to develop northern health research capacity by establishing the first Canadian tri-territorial health research network in 2005 (Butler Walker et al., 2011; Chatwood and Young, 2010). More efforts to build northern health research capacity are needed, however. These efforts could include supporting community-based health research, addressing the health priorities of the Indigenous population within the field of social science, advancing systems science and research focused on remote and rural service delivery, and facilitating strategic partnerships in national health research projects. Examining the social determinants of health and mental health, the relationship between housing and socioeconomic conditions, and the food security implications of climate change will help to advance our understanding of health care systems (Young, 2003; Wilson and Young, 2008; Canadian Polar Commission, 2014). Northern Indigenous organizations have also noted the need for more partnership-based health research (e.g., ITK, 2016).

\section{Foster Partnerships}

Cooperating in the development and exchange of scientific information is essential. Through partnerships across departments, organizations, jurisdictions, circumpolar nations, and disciplines, participants can bring together their capabilities, interests, expertise, and resources. This collaboration will help to achieve advancements in knowledge and understanding that are not possible when parties work in isolation. Partnerships also accelerate the pace of knowledge gathering and make the best use of limited resources. In April 2016, the Government of Yukon signed on to the Pan Northern Approach to Science (PNAS) (GY, GNWT and GN, 2016), which emphasizes the importance of territorial partnerships to advancing northern interests and outlines the key elements that a scientific system requires to maximize the benefits of scientific endeavours to people, environments, and economies of the North.

Development of meaningful community-researcher partnerships is of particular interest across the North. Historically, the predominant approach to conducting research in the North has been for southern-based academic researchers to develop a proposal themselves. If the project is funded, then the researchers travel north to the community they want to work in to implement their project. This scenario is sometimes called community-based research, but it's actually more accurately described as communityplaced research, since the community has not been meaningfully engaged in all stages of the research process, and the topic may or may not be a community priority (J. Butler Walker, Arctic Institute of Community-based Research, pers. comm. 2016). The importance of fostering meaningful community partnerships has been eloquently articulated by many northern communities and researchers; however, as noted by Brunet et al. (2014b, 2016) and Moffit et al. (2015), there is still much to be done to promote effective partnerships at the local level. Interestingly, in a recent survey of Yukon's Science Community of Practice (SCOPe), 70\% of respondents cited an interest in enhancing collaboration and cooperation on science-based activities as a reason for joining SCOPe (Westfall, 2014).

Not long ago, Canadian academics were considered to lack the resources to initiate significant northern research that would attract international interest and collaboration (Task Force on Northern Research, 2000). The International Polar Year and ArcticNet have facilitated substantial progress in this respect (INAC, 2012; ArcticNet, 2015). POLAR has a mandate to build on and further develop these international partnerships, but will be challenged to align international interests with local needs.

\section{Establish and Maintain a Strong Yukon-based Science Community}

Human capital is fundamental to any scientific endeavour. It is essential to create and maintain a professional intellectual environment that will attract, promote, and 
support research and science. Local knowledge creation is recognized as critical to building and sustaining socioeconomic welfare: "In the long run, no region or nation can remain a simple 'user' of new knowledge, but also must become a 'creator' of new knowledge" (UNESCO, 2015:4). In Yukon, SCOPe was established in 2013 to promote networking of Yukon's science practitioners and support their professional development. A 2014 survey of SCOPe members found that the educational attainment of the respondents was quite high: $42 \%$ have a master's degree, and $26 \%$ have a doctorate, suggesting that a strong, Yukon-based science community already exists (Westfall, 2014).

\section{ADVANCING YUKON SCIENCE}

The Government of Yukon Science Strategy outlines six long-term goals and associated near-term strategic initiatives to support the active pursuit, gathering, and storage of scientific knowledge so it can be easily retrieved, transferred, shared, and used to support evidence-based decision making (Table 1). Each of these goals is discussed below within a broader northern context.

\section{Support Decision Making}

At the very heart of Government of Yukon's vision to support evidence-based decision making is the ability to 1) identify, communicate and address the science needs of decision makers, 2) conduct the research needed to inform decision making, 3) effectively link science to policy development and decision making, and 4) produce science that is both accessible and understandable. The past decade of Arctic research has largely failed to address some scientific goals identified by policy makers and residents and has not succeeded in finding ways to help stakeholders cope with the changing environment (Ibarguchi et al., 2015; Rosen, 2016). A balance is needed between pure, curiosity-driven science and solution-oriented, partnership-based science that is responsive to the needs of Northerners (GY, GNWT and GN, 2016). Northern priorities and input must be reflected in the development and delivery of all northern science programs.

\section{Build Science Capacity}

The state of Canada's northern research 15 years ago resulted in calls for greater investments in training and capacity building to generate knowledge in the North, for the North. Since that time a number of efforts have been made, both large and small, to enhance northern research capacity. The term "capacity building," while commonly used, does not have a common meaning. To many it means developing highly qualified personnel, individuals who have obtained a minimum of a Bachelor's degree from an educational institute (Hughes, 2012). But does this definition meet the needs of northern Canadians? Both the Government of Yukon Science Strategy and the PanNorthern Approach to Science use a broader definition that includes accessing, applying, and developing scientific knowledge, and, like the Task Force on Northern Research (2000), both emphasize the importance of developing northern science capacity.

Yukon University will provide a hybrid model for developing highly qualified personnel to meet Yukon needs in the trades, technical, and related fields as well as in academic fields, granting both technical diplomas and degrees. Combined with well-articulated scientific research objectives, long-term monitoring, and the engagement of community-based highly qualified personnel, Yukon can be at the forefront of developing a northern-based research program that will meet the need of Northerners. The concept of peer-reviewed science can and should expand to include review by those reliant on the outcomes, thereby integrating conventional criteria of validity with non-scientific criteria of usefulness (Brunet et al., 2014a). Where better to implement this shift in thinking than in a northern setting that is facing unparalleled challenges on many fronts? The change would provide a new way to develop highly qualified persons in the North, and ensure that scientific results are valid in a northern context would increase their benefit to Northerners.

\section{Improve Data Collection and Management}

The ultimate aim of efforts to improve data collection, recovery, and management is to allow scientific data to be easily retrieved, transferred, shared, and used. This improvement requires enhancing baseline and long-term data collection, standardizing data collection protocols, enhancing data openness, preserving data for long-term use, undertaking data management planning, and increasing collaboration on data management on local to global scales. Long-term monitoring and data recovery, including the recording of traditional knowledge, are key to understanding the profound changes currently taking place in the North. They are essential to underpin current research and knowledge gathering and to provide the long-term baseline data sets required to identify shifting anomalies, to support decision making, and to mitigate the impact of climate and social changes.

Research projects are often planned to last two to four years in order to meet the criteria of funding agencies. Very few projects can sustain long-term (decadal) research or monitoring. While short-term research projects can contribute to monitoring, they cannot carry the full burden. In fact, it can be argued that the reverse is true: that a well-funded and sustained program for monitoring, data collection, and archiving will attract new research and researchers to Yukon and thus contribute to Yukon's economy, as well as being of immense benefit to Yukon University and to Yukoners. Developing a coordinated, sustained, and wellfunded effort to monitor key physical and social parameters is essential. In combination with historical data, such 
monitoring will establish baseline conditions and identify key trends to support decision making in Yukon. Community-based monitoring is seen as an ideal way to engage Northerners and is already proving its worth in many communities. It is integral to a hybrid monitoring model that also uses remote sensing data, as well as networks of ground-based sensors, both of which require robust data communication networks to collect, share, and use the data.

\section{Stimulate Private and Civil Sector Science}

In Canada, federal government agencies fund about $10 \%$ and universities $40 \%$ of all R\&D. The business enterprise sector funds and performs the other half (Dufor, 2015). Nationally, business investment in R\&D has been declining, with a corresponding decline in industrial $R \& D$ jobs. Recent assessments commissioned by the Council of Canadian Academies and Industry Canada show that relative to the size of the Canadian economy, government support for business R\&D in Canada is among the most generous in the world, yet the opposite is true with respect to business investment in R\&D. These assessments concluded that Canada needs to do a better job helping innovative Canadian small to medium-sized businesses grow into larger, world-competitive companies, and address barriers to taking advantage of this country's innovations (CCA, 2009, 2013; Industry Canada, 2011).

Stimulating private and civil sector science involves promoting and encouraging innovation and commercialization, supporting and encouraging R\&D investment by the private sector, supporting knowledge sector business development, supporting the development of science and technology as a secondary industry, supporting scientific partnerships with industry, and creating a policy environment that is flexible enough to respond to, adapt to, and encourage innovation. Support for the Cold Climate Innovation program at Yukon College and the Yukon Information and Communications Technology Sector are important elements of the Government of Yukon's plan to stimulate private and civil sector science.

\section{Promote Information Sharing}

Science must be accessible to be used. Agencies must assess the effectiveness of their approaches to sharing scientific information, as well as the means by which they access reliable scientific information from other agencies, and how this access can be enhanced. The science strategy commits the Government of Yukon to increasing publication of its scientific work and enhancing sharing of information (both within and outside government) and outreach activities. An online Compendium of Current Yukon Research and Monitoring is in development to promote sharing of information.

\section{Manage and Enhance Science Conduct}

For science to be able to inform policy, a policy environment is needed that enables scientific activity, enhances scientific coordination, and facilitates and promotes scientific excellence. The last goal of the Government of Yukon Science Strategy is to manage science conduct through consistent government-wide policies and procedures, including standardization of data capture funded by government and collected by outside agencies. Such oversight of scientific activity would promote scientific excellence in Yukon.

\section{CONCLUSIONS}

Canada's North has entered into a period of unprecedented change that presents both opportunities and challenges to northern governments. Similarly, the current focus on reconciliation presents an opportunity and obligation to do research differently. Scientific research and knowledge-gathering activities that provide sound and reliable evidence-based information and contribute to innovative solutions are essential to help manage these challenges. Keys to success include fostering a strong, locally based scientific community with the capacity to work at the interface of science and traditional knowledge, at the interface of knowledge (both scientific and traditional) with policy, and within the modern northern research paradigm that demands research to be co-designed, co-produced, and shared through meaningful partnerships.

The ability to tackle the issues important to Yukoners, from sustainable resource development to quality health care and education, requires a strong science base and a capacity to innovate. While Yukon has a long history of scientific activity, the need for relevant scientific information continues to grow. Much of this history has been driven by the research objectives of outside organizations, which often do not target needs identified by Yukoners. Our ability to cope with the challenges posed by demographic change, accelerating climate change, population growth, and globalization is linked to our ability to respond in relevant ways.

Science activities in Yukon have traditionally occurred in the absence of an overarching strategy that more often than not has impeded efficient cost sharing. Efforts to focus and connect ongoing scientific research and technology innovation to established priorities and objectives will allow us to be better integrated and foster the cooperation needed to meet the greater needs of those within and outside the jurisdiction. 


\section{REFERENCES}

ArcticNet. 2015. ArcticNet Annual Report: 2014-2015. http://www.arcticnet.ulaval.ca/pdf/media/2015-annual-reporten.pdf

Barnes, K., and Graham, A. 2015. Yukon College EditorialPoised for the next step: University. The Northern Review 40:3-8.

Benkert, B.E., Kennedy, K., Fortier, D., Lewkowicz, A., Roy, L.-P., Grandmont, K., de Grandpré, I., Laxton, S., McKenna, K., and Moote, K. 2015. Dawson City landscape hazards: Geoscience mapping for climate change adaptation planning. Whitehorse: Northern Climate ExChange, Yukon Research Centre, Yukon College.

Brunet, N.D., Hickey, G.M., and Humphries, M.M. 2014a. The evolution of local participation and the mode of knowledge production in Arctic research. Ecology and Society 19(2): 69. http://dx.doi.org/10.5751/ES-06641-190269

2014b. Understanding community-researcher partnerships in the natural sciences: A case study from the Arctic. Journal of Rural Studies 36:247-261. http://dx.doi.org/10.1016/j.jrurstud.2014.09.001

— 2016. Local participation and partnership development in Canada's Arctic research: Challenges and opportunities in an age of empowerment and self-determination. Polar Record 52(3):345-359.

http://dx.doi.org/10.1017/S003224741500090X

Butler Walker, J., Kassi, N., Friendship, K., Blottner, B., and Van Bibber, M. 2011. Arctic Health Research Network-Yukon Highlights Report 2007-2011. Whitehorse, Yukon. 54 p.

http://www.aicbr.ca/reports/

Callaghan, T.V., Johnasson, M., Pchelintseva, Y., and Kirpotin, S.N. 2015. Scientific cooperation throughout the Arctic: The INTERACT Experience. In: Evengård, B., Nymand Larsen, J., and Paasche, Ø., eds. The New Arctic. Cham, Switzerland: Springer. 269-289.

Calmels, F., Roy, L.-P., Laurent, C., Pelletier, M., Kinnear, L., Benkert, B., Horton, B., and Pumple, J. 2015. Vulnerability of the North Alaska Highway to permafrost thaw: A field guide and data synthesis. Whitehorse: Northern Climate ExChange, Yukon Research Centre, Yukon College.

https://yukoncollege.yk.ca/research/abstracts/vulnerability_ of_the_north_alaska_highway_to_permafrost thaw

Canadian Polar Commission. 2014. The state of northern knowledge in Canada. Ottawa: Canadian Polar Commission. $42 \mathrm{p}$.

http://www.polarcom.gc.ca/sites/default/files/snk_report_ english.pdf

Carr, K., Natcher, D.C., and Olfert, R. 2013. Measuring the economic impact of publicly funded research in northern Canada. Polar Geography 36(4):291 -304. http://dx.doi.org/10.1080/1088937X.2013.826746
CCA (Council of Canadian Academies). 2008. Vision for the Canadian Arctic Research Initiative: Assessing the opportunities. Report of the International Expert Panel on Science Priorities for the Canadian Arctic Research Initiative. Ottawa: CCA.

http://www.scienceadvice.ca/en/assessments/completed/ canadian-arctic.aspx

. 2009. Innovation and business strategy: Why Canada falls short. Report of the Expert Panel on Business Innovation. Ottawa: CCA.

http://www.scienceadvice.ca/en/assessments/completed/ innovation.aspx

2013. The state of industrial R\&D in Canada. Report of the Expert Panel on the State of Industrial R\&D. Ottawa: CCA. http://scienceadvice.ca/en/assessments/completed/research_ development.aspx

- 2014. Science culture: Where Canada stands. Report of the Expert Panel on the State of Canada's Science Culture. Ottawa: CCA.

http://www.scienceadvice.ca/en/assessments/completed/ science-culture.aspx

Chatwood, S., and Young, K. 2010. A new approach to health research in Canada's North. Canadian Journal of Public Health 101(1):25-27.

Côté, G., and Picard-Aitken, M. 2009. Arctic research in Canada: A bibliometric analysis. Submitted to Indian and Northern Affairs Canada. Montreal, Quebec: Science-Metrix. 23 p.

Council for Yukon Indians. 1973. Together today for our children tomorrow: A statement of grievances and an approach to settlement by the Yukon Indian People. Whitehorse: Council for Yukon Indians.

http://www.eco.gov.yk.ca/pdf/together_today_for_our_ children_tomorrow.pdf

Cruikshank, J. 1981. Legend and landscape: Convergence of oral and scientific traditions in the Yukon Territory. Arctic Anthropology 18(2):67-93.

Dufor, P. 2015. Canada. In: UNESCO Science Report: Towards 2030. Chapter 4. Paris: UNESCO. 106-127. http://unesdoc.unesco.org/images/0023/002354/235406e.pdf

Easton, N.A. 2008. Establishing the Northern Research Institute: A personal recollection. The Northern Review 29:151-158.

Giles, A. 2014. Commentary: Making the case for increased funding for social sciences and humanities research in northern Canada. Polar Record 51(2):215-218. http://dx.doi.org/10.1017/S0032247414000539

GC (Government of Canada). 2007. Canadian IPY 2007-2008 data policy. http://www.api-ipy.gc.ca/pg_IPYAPI_055-eng.html

GC, CYI and GY (Government of Canada, Council for Yukon Indians and Government of Yukon). 1993. Umbrella Final Agreement.

http://cyfn.ca/wp-content/uploads/2013/08/umbrella-finalagreement.pdf 
GY (Government of Yukon). 1986. Yukon Science Policy. Whitehorse: Executive Council Office, Government of Yukon. . 2016a. Government of Yukon science strategy. Whitehorse: Executive Council Office, Government of Yukon. http://www.eco.gov.yk.ca/science/science-strategy.html

- 2016b. Yukon research facilities. Whitehorse: Executive Council Office, Government of Yukon.

http://www.eco.gov.yk.ca/science/yukonresearchfacilities. html

- 2016c. Northern science databases. Whitehorse: Executive Council Office, Government of Yukon. http://www.eco.gov.yk.ca/science/resources.html

GY, GNWT and GN (Government of Yukon, Government of Northwest Territories and Government of Nunavut). 2016. A pan-northern approach to science. $23 \mathrm{p}$.

http://www.anorthernvision.ca/documents/A16_Brochure PanNorthernApproachtoScience_71402_English_WEB-Final. pdf

Hik, D. 2009. A northern science policy for Canada. 2030 North: National Planning Conference, Session Paper No. 4. Ottawa: Canadian Arctic Resources Committee. 13 p.

Hughes, C.M. 2012. A study on the career advancement and retention of highly qualified women in the Canadian mining industry. MAS thesis, Faculty of Graduate Studies (Mining Engineering), University of British Columbia.

IASC (International Arctic Science Committee). 2013. Statement of principles and practices for Arctic data management. http://iasc.info/data-observations/iasc-data-statement

IASSA (International Arctic Social Sciences Association). 2016. ICASS IX: Call for sessions for the 9th International Congress of Arctic Social Sciences.

http://iassa.org/icass-ix

Ibarguchi, G., Murray, M.S., Rajdev, V., and ISAC International Program Office. 2015. Does funding for Arctic research align with research priorities and policy needs? Trends in the USA, Canada and Europe. AGU Fall Meeting, 14-18 December 2015, San Francisco, California.

https://agu.confex.com/agu/fm15/webprogram/Paper64944. html

INAC (Indigenous and Northern Affairs Canada). 2012. Evaluation of the Government of Canada Program for International Polar Year. Ottawa: INAC. 75 p.

https://www.aadnc-aandc.gc.ca/eng/1380125742927/13801258 28382

Industry Canada. 2011. Innovation Canada: A call to action. Review of Federal Support to Research and Development Expert Panel Report. Ottawa: Industry Canada. 148 p. http://www.rd-review.ca

IPCC (Intergovernmental Panel on Climate Change). 2014. Climate change 2014: Impacts, adaptation, and vulnerability. Working Group II Contribution to the Fifth Assessment Report of the Intergovernmental Panel on Climate Change. Cambridge: Cambridge University Press.

ITK (Inuit Tapiriit Kanatami). 2016. 2016-2019 Strategy and Action Plan. Ottawa: ITK.

https://www.itk.ca/publication/2016-2019-strategy-andaction-plan
Moffitt, M., Chetwynd, C., and Todd, Z. 2015. Interrupting the northern research industry: Why northern research should be in northern hands. Northern Public Affairs 4(1).

http://www.northernpublicaffairs.ca/index/interrupting-thenorthern-research-industry-why-northern-research-should-bein-northern-hands/

NAHO (National Aboriginal Health Organization). 2005. Ownership, control, access and possession (OCAP) or selfdetermination applied to research: A critical analysis of contemporary First Nations research and some options for First Nations communities. Prepared for the First Nations Information Governance Centre, Ottawa. http://www.naho.ca/documents/fnc/english/FNC OCAPCriticalAnalysis.pdf

Ogden, A., and Thomas, M.E. 2013. Letter to the Editor re: the Lakehead Manifesto. Arctic 66(4):508.

Perrin, A., Dion, J., Eng, S., Sawyer, D., Nodelman, J.R., Comer, N., Auld, H., et al. 2015. Economic implications of climate change: Adaptations for mine access roads in northern Canada. Whitehorse: Northern Climate ExChange, Yukon Research Centre, Yukon College. 93 p.

Pope, S. 2015. Implementation science: S\&T into action. Presentation to the Yukon Science Community of Practice, 1 April 1 2015, Whitehorse.

Rosen, J. 2016. Arctic research slow to focus on societal needs. Arctic Deeply https://www.newsdeeply.com/arctic/articles/2016/01/28/arcticresearch-slow-to-focus-on-societal-needs/

Russel, D.E., Svoboda, M.Y., Arokium, J., and Cooley, D. 2013. Arctic Borderlands Ecological Knowledge Cooperative: Can local knowledge inform caribou management? Rangifer Special Issue 33(Special Issue 21):71-78.

Schuster, R.C., Gamberg, M., Dickson, C., and Chan, H.M. 2011. Assessing risk of mercury exposure and nutritional benefits of consumption of caribou (Rangifer tarandus) in the Vuntut Gwitchin First Nation community of Old Crow, Yukon, Canada. Environmental Research 111(6):881 - 887. http://dx.doi.org/10.1016/j.envres.2011.05.025

Sloan, K.K., and Hik, D. 2007. International Polar Year as a catalyst for sustaining Arctic research. Sustainable Development Law \& Policy 8(3):4-7, 59.

Southcott, C. 2011. A vision: The future of scientific work in the Arctic in 2021. Shared Voices: The University of the Arctic Magazine.

http://www.uarctic.org/media/13289/Shared_Voices_ Magazine_2011_screen_5JxZY.pdf

Southcott, C., Walker, V., Natcher, D., Alsop, J., Jeans, T., and Falvo, N. 2011. Researching the social economy in Canada's North: Reflections on the node partnerships and processes. In: Hall, P.V., and MacPherson, I., eds. Community-university research partnerships: Reflections on the Canadian social economy experience. Chapter 9. Victoria, BC: University of Victoria. 181-204.

https://dspace.library.uvic.ca/bitstream/handle/1828/3878/ SE\%20Book_print.pdf?sequence $=1 \&$ isAllowed $=y$ 
Stewart, K.J., and Janin, A. 2014. Leonardite and biochar for mine impacted water and soils. Technical Report prepared for Wapaw Bay Resources. Whitehorse: Yukon Research Centre, Yukon College. 21 p.

Task Force on Northern Research. 2000. From crisis to opportunity: Rebuilding Canada's role in northern research. Final report to the NSERC and SSHRC Task Force on Northern Research. Ottawa: NSERC and SSHRC.

http://www.nserc-crsng.gc.ca/_doc/Northern-Nordique/crisis. pdf

Tondu, J.M.E., Balasubramaniam, A.M., Chavarie, L., Gantner, N., Knopp, J.A., Provencher, J.F., Wong, P.B.Y., and Simmons, D. 2014. Working with northern communities to build collaborative research partnerships: Perspectives from early career researchers. Arctic 67(3):419-429.

UNESCO (United Nations Educational, Scientific and Cultural Organzation). 2015. UNESCO Science Report: Towards 2030. UNESCO, Paris, France. 795 p. http://unesdoc.unesco.org/images/0023/002354/235406e.pdf

Universities Canada. 2015. Canada's universities' commitments to Canadians.

http://www.univcan.ca/media-room/publications/canadasuniversities-commitments-to-canadians/

Wesche, S., Schuster, R.C., Tobin, P., Dickson, C., Matthiessen, D., Graupe, S., Williams, M., and Chan, H.M. 2011. Communitybased health research led by the Vuntut Gwitchin First Nation. International Journal of Circumpolar Health 70(4):396-406.

Westfall, R. 2014. Science Community of Practice Membership Survey, 2014. Whitehorse: Yukon Bureau of Statistics, Government of Yukon. 25 p. http://www.eco.gov.yk.ca/pdf/2014_SCOPe_Survey_Report. pdf
Wilson, K., and Young, T.K. 2008. An overview of Aboriginal health research in the social sciences: Current trends and future directions. Journal of Circumpolar Health 67(2-3):179-189.

Wolfe, B.B., Humphries, M., Pisaric, M.F.J., Balasubramaniam, A.M., Burn, C.R., Chan, L., Cooley, D., et al. 2011. Environmental change and traditional use of the Old Crow Flats in northern Canada: An IPY opportunity to meet the challenges of the new northern research paradigm. Arctic 64(1):127-135. http://dx.doi.org/10.14430/arctic4092

YC (Yukon College). 2016. Yukon College University Planning: Success for generations to come. https://www.yukoncollege.yk.ca/universityplanning

Young, T.K. 2003. Review of research on Aboriginal populations in Canada: Relevance to their health needs. The BMJ 327:419-422. http://dx.doi.org/10.1136/bmj.327.7412.419

Young, T.K., and Chatwood, S. 2011. Health care in the North: What Canada can learn from its circumpolar neighbours. Canadian Medical Association Journal 183(2):209-214. http://doi.org/10.1503/cmaj.100948

Aynslie E. Ogden is Senior Science Advisor, Executive Council Office, Government of Yukon; Michael Schmidt is Science Coordinator, Kluane Lake Research Station, Arctic Institute of North America; Bob Van Dijken is Director of Circumpolar Relations, Council of Yukon First Nations; and Lacia Kinnear is Director of Strategic Growth and Innovation, Yukon College Corresponding author: Aynslie.Ogden@gov.yk.ca 